\title{
ГУМАНИТАРНЫЕ НАУКИ И ГУМАНИТАРНОЕ ОБРАЗОВАНИЕ В МИРЕ ЦИФРОВОЙ КУЛЬТУРЫ: ВОПРОСЫ ТРАНСФОРМАЦИИ
}

\author{
Дулатова Анна Николаевна \\ Д.П.н., профессор \\ Рюмшина Елена Владимировна \\ к.П.н., доцент \\ Матвеева Анастасия Сергеевна \\ к.П.н., доцент
} ФГБОУ ВО «Краснодарский государственный институт культуры»

Аннотация: В статье анализируются направления трансформации гуманитарных наук в контексте идей синергетики и внедрения конвергентных технологий в образование. Рассмотрено соответствие синергетической парадигмы гуманитарным проблемам современной цивилизации. Предложены подходы к конвергентному образованию в условиях развития общества цифровой культуры.

Ключевые слова: Трансформация, синергетика, конвергенция, цифровизация, гуманитарные науки, гуманитарное образование.

\section{HUMANITIES AND HUMANITIES EDUCATION IN THE WORLD OF DIGITAL CULTURE: ISSUES OF TRANSFORMATION}

\author{
Dulatova Anna Nikolaevna \\ Ryumshina Elena Vladimirovna \\ Matveeva Anastasia Sergeevna
}

\begin{abstract}
The article analyzes the directions of transformation of the humanities in the context of the ideas of synergetics and the introduction of convergent technologies in education. The correspondence of the synergetic paradigm to the humanitarian problems of modern civilization is considered. Approaches to convergent education in the context of the development of a digital culture society are proposed.
\end{abstract}

Key words: Transformation, synergy, convergence, digitalization, humanities, humanities education. 
Цифровизация - эффективнейший продукт технологической революции имеет множество преференций и такое же множество рисков для социально и экономически обусловленных процессов потребления. В данном случае мы имеем в виду непроизводственное (общественное и личное) потребление в современной гуманитарной науке и современном гуманитарном высшем образовании.

Гуманитарная сфера всегда была и остается одной из самых уязвимых для научного осмысления и прогнозирования, оценки продуктов деятельности, анализа профессионального труда, профессиональной подготовки и др. Гуманитарные науки не имеют четких границ в отечественных и зарубежных классификациях наук. Соответственно многие специальности, определяемые как гуманитарные, гуманитаристика и высшая школа относят к разным классификационным схемам. Сравнительно недавно гуманитарные и негуманитарные науки могли даже выступать по отношению друг к другу в ролях антагонистов. Уместно вспомнить, что противостояние представителей технократической и гуманитарной культур («физиков» и «лириков») продолжается с прошлых веков. Эта общемировая проблема до сих пор не решена. А с переходом к цифровым технологиям она приобрела еще один предмет исследований: социокультурные трансформации и цифровизация. Данная предметная область направлена на поиск техно-гуманитарного взаимодействия в цифровом обществе. Сегодня осознаны и проектируются инновационные перспективные решения, составляются долгосрочные прогнозы развития человечества в мире цифровой культуры. Наука констатирует, что цифровые технологии формируют целостный взгляд на картину мира, меняют общественное и профессиональное сознание. Среди многих условий эффективного развития цифровой культуры к важнейшим, по нашему мнению относятся:

- во-первых, создание синергетической модели мира и ее отражение в познании, культуре в целом;

- во-вторых, конвергенция как сохранение техно-гуманитарного баланса в науке и образовании.

Рассмотрим по этим направлениям некоторые аспекты трансформации и перспектив развития гуманитарных наук и гуманитарного образования.

1. Синергетическая модель мира.

Почему из всех существовавших и действующих образовательных парадигм синергетическая парадигма нам представляется наиболее перспективной для цифровой культуры? Не только потому, что 
образовательная практика показала однонаправленность, несоответствие современному социальному запросу апробированных парадигм (социетарной, технократической, культурологической, естественнонаучной, когнитивной и др.). Действующая компетентностная парадигма, изначально неоднозначно оцениваемая российской высшей школой, не принесла ожидаемых результатов, оказалась фактически «достройкой» к когнитивной (ЗУНовской) системе. ЗУНовская образовательная парадигма, почти три столетия обеспечивавшая мировой институт познания, в условиях системной трансформации нашего общества требует радикальной перестройки, иначе теряет перспективу.

Синергетическая образовательная парадигма отвечает требованиям инновационного познания. Социокультурные трансформации гуманитарной сферы прошлого и нынешнего времени обусловили новую идею освоения мира. Если до конца прошлого столетия эволюция познающего человека определялась только науками, то синергетическая теория положила начало изучению жизни единством всех существующих способов: философии, науки, религии, мифологии, искусства и др. Это означает, что традиционная модель «наука-образование-практика» с ее логико-вербальным мышлением уступает место открытой модели познания. Иными словами, синергетическая парадигма отражает системную трансформацию современной цивилизации. Она соответствует:

- идее открытого высшего образования;

- формированию холизма в мышлении;

- инновационности педагогических технологий;

- направленности образовательного процесса на гуманизацию познания, на эмоциональность восприятия и рефлексивность.

Bсе это доказывает способность данной парадигмы к преодолению рисков интеллектуального потребительства, провоцируемого цифровой средой и не такой далекой реальностью смарт-мира, в котором человеческая раса отдаст искусственному интеллекту свои приоритеты в труде, мышлении и, возможно, творчестве. Однако, несмотря на свою фундаментальность и неоспоримую адекватность потребностям новой цивилизации, синергетическая модель чрезвычайно редко внедряется в образовательную практику. Одной из главных причин является необходимость полной, революционной экономической перестройки организации, структуры, всего содержания института образования. В теоретико-методологическом плане это отказ от 
преобладания методов дифференциации познания, внедрение новых, не только научных способов освоения действительности. Определяющей стратегией становится интеграция, направленная на преодоление разорванности общественного сознания, внутренней разобщенности каждой мыслящей личности. Перестраивается учебно-методический инструментарий, его содержание, типовидовая, жанровая структура. Намечается переход от освоения отдельных учебных дисциплин, которые веками строились в зависимости от дифференциации наук, к изучению глобальных проблем человечества.

Обязательным условием внедрения синергетической парадигмы является изменение мышления субъектов образовательного процесса. Имеется в виду переход преподавателя к холистическому (сложному нелинейному) мышлению и формирование подобного мышления студентом. Холизм, новая фундаментальная научная концепция, отличается такими качествами как целостность, инновационность, системность, оценочность, прогностический подход к познанию.

Холизм мышления является предметом ключевых исследований для многих гуманитарных и негуманитарных наук, отражается в таких важнейших социальных явлениях как культурная конвергенция, глобализация, интернационализация и др. В высшей школе он признан актуальным средством формирования целостного мышления, прогностической компетенции, широты тезауруса студента. Педагогу перестраивать профессиональное сознание намного труднее. Отсюда при неорганизованном планировании на этапе внедрения синергетической концепции в образование можно прогнозировать риск кадрового голода. Но значимость холизма для развития современной жизнедеятельности говорит о том, что при любой действующей системе оно должно пронизывать любую образовательную технологию, полно отражаться в нормативной документации, образовательных стандартах, образовательных программах высшей школы.

Мы не утверждаем, что синергетическая парадигма эталонная модель. Как любая образовательная система она должна пройти проверку временем, будет эффективна и востребована до тех пор, пока отвечает запросам своей цивилизации. Но совокупность ее базовых установок адекватна формирующейся инновационной концепции восприятия и освоения окружающего нас мира. Это понимали еще в прошлом веке российские 
исследователи гуманизации высшего образования. В 80-90 годы ученые получили положительный эффект от междисциплинарных экспериментов по внедрению синергетической парадигмы в образование [1,2]. В настоящее время идея синергии распространяется за рубежом. Например, в Финляндии средняя общеобразовательная школа переходит к междисциплинарному изучению предметов и явлений действительности, причем традиционное преподавание отдельных дисциплин рассматривается как устаревшая методика [3].

2. Конвергенция как сохранение техно-гуманитарного баланса.

Взаимодействие науки и образования (известное за рубежом как «русский метод») является традиционной стратегией отечественной высшей школы. Поскольку наука сохраняет все свои приоритеты, свой статус фундамента познания, институт образования «копирует» ее достижения, риски и просчеты. Так, главным направлением развития науки является конвергенция как составляющая общей культурной конвергенции во всех ее проявлениях и необозримом множестве форм. Идея культурной конвергенции существует издавна, а с XIX века начала оформляться в теоретическую дисциплину. Для науки данный процесс стал необратимым и многими рассматривается как безальтернативный способ спасения человеческой цивилизации [4]. На конвергентном этапе развития науки в предмет изучения и внедрения результатов в практику входят вопросы:

- сближения и взаимодействия наук;

- сближения и взаимодействия наук и технологий;

- новых подходов к сближению и взаимодействию науки с образованием;

- конвергентных методов фундаментальных и прикладных научных исследований и др.

Таким образом, идет активное создание теоретико-методологической базы конвергенции наук, конвергенции наук и технологий. Очевидно, что на культурные, социальные, экономические трансформации, порождающие новую парадигму науки, конвергенция оказывает заметное влияние.

Теория конвергенции уделяет все больше внимания проблемам сближения и взаимодействия гуманитарного и негуманитарного знания. В научной среде статус гуманитарного знания заметно повысился. Ярким примером трансформации гуманитарного знания может служить конвергенция гуманитарных наук и технологий. Это разработка моделей цифровых гуманитарных наук в области применения новых цифровых технологий для 
исследования социально-гуманитарного знания. Стремительная цифровизация обусловила неоднозначность ответа на нее всех социальных институтов и всех процессов деятельности. Амбивалентность, неопределенность оценок проявляется в управлении, организации труда, научной интерпретации и моделировании производства, естественно, и в образовании. В данных условиях совместная деятельность становится единственным оперативным и эффективным способом. Отсюда все теснее взаимодействие гуманитарных наук внутри структуры гуманитаристики и такое же активное сближение гуманитарных наук с негуманитарными науками, гуманитарных наук с цифровыми технологиями, специальных гуманитарных методов с методами интернет-исследований и др. Показателем трансформационной активности цифрового гуманитарного знания являются новые практики «гуманитарные науки 2.0». Е.Ю. Журавлева, анализируя зарубежный опыт вовлечения исследователей в междисциплинарное поле цифровых гуманитарных наук, подчеркивает, что «цифровые гуманитарные науки» 2.0 внедряются в новые конвергентные области и гибридные методологии, позволяющие встраивать изначально цифровые продукты в традиционные гуманитарные результаты [5].

Используя цифровые модели, гуманитаристика получила инструментарий для результативных конвергентных исследований. При этом наибольшую трансформационную активность проявляют те гуманитарные науки, объектом и предметом которых является документ, поскольку процесс цифровизации есть процесс перевода документированной информации в новую форму. И на новом цифровом носителе текст документа остается безальтернативным средством передачи информации. При этом традиционный бумажный документ преобразован настолько радикально, необратимо, что теряет узаконенное и принятое большинством определение своего понятия. Тезаурус гуманитаристики постоянно расширяется за счет таких терминов и понятий как «гуманитарные вычисления», «гуманитарные цифровые науки», «кибергуманитарные науки», «гуманитарная информатика», «цифровое литературоведение», «мультимодальные гуманитарные науки» и многих других. Тезаурус любой сферы деятельности есть не только исчерпывающая система данных (терминов, определений понятий, дескрипторов, кодов, знаков и т.п.), семантических отношений между ними. Он всегда отражает и социокультурную жизнедеятельность своего времени и ее трансформации. 
Поскольку передовым направлением науки и практики становится конвергенция, тезаурус иллюстрирует междисциплинарные отношения в любой отдельной области деятельности. Сближение и взаимодействие концепций, технологий, методов его не только модернизируют. Множество конвергентных составляющих преобразуют тезаурус фактически в новую модель свернутого знания о его предметной области. Сегодня можно видеть, как эта трансформация оказывает влияние на социально-экономическую сферу, в том числе, на профессиональный труд. Здесь тезаурус должен интерпретироваться как самостоятельная база систематизированной информации о прошлом, настоящем и даже будущем конкретной профессии. Однако данное утверждение часто может рассматриваться лишь в качестве постулата применительно к ряду гуманитарных профессий. В целом терминосистема гуманитаристики еще находится в состоянии неопределенности, мало пополняется за счет взаимодействия с терминосистемами родственных отраслей и очень слабо с частыми ошибками конвергирует с терминосистемами негуманитарной сферы.

Таким образом, современное научное знание есть единство гуманитарного, естественнонаучного и технического знания в конвергентном восприятии мира. И это является единственно верной предпосылкой перспективного развития высшей школы.

В образовании трансформационная активность выражается в таких процессах, как междисциплинарность, трансдисциплинарность, базирующихся на конвергенции наук. Отдельные аспекты этой проблемы изложены нами ранее [6].

Конвергентное научное знание в образовании обеспечивает сближение и взаимодействие учебных дисциплин и технологий для целостного восприятия мира обучающимися. Главный педагогический прием - осмысление и оценка конкретного явления или предмета в разных интерпретациях. Главный инструмент персональной траектории развития студента - формирование когнитивно-информационной. Для гуманитарной высшей школы это означает переосмысление традиционных теоретико-методологических подходов к учебному процессу, его методическому, научному и техническому обеспечению. Результатом этой радикальной, перестройки станут новые конвергентные «продукты» образования - кадры, готовые к профессиональной деятельности в цифровом обществе. Мы предполагаем следующий алгоритм 
начального этапа перехода гуманитарного образования к конвергентному познанию:

- обеспечение учебного процесса систематическим теоретическим знанием о синергетической парадигме освоения мира; о конвергенции наук; о конвергенции наук и технологий; о конвергенции науки и образования;

- направленность образовательных программ на формирование студентами компетенций холизма;

- внедрение конвергентных методов в преподавание традиционных учебных дисциплин;

- перестройка структуры и содержания учебно-методического инструментария традиционных дисциплин;

- создание и внедрение конвергентных учебных курсов и соответствующего им учебно-методического инструментария;

- подготовка и переподготовка педагогических кадров в контексте синергетической парадигмы и конвергентной методологии;

- трансформация научных исследований вуза в направлении фундаментальных идей культурной конвергенции и реализация научного продукта в практике профессиональной деятельности.

Нельзя откладывать проблемы конвергентного подхода к высшему образованию в ожидании специальных указаний, административных мер, нормативов и т.п. Инновационность, конкурентоспособность, уровень качества обучения вуза сегодня зависят от его инициативности, трансформационной активности, смелости прогнозирования.

Гуманитаристика должна иметь множество проектов перехода к открытому образованию для создания выводного знания и его наиболее перспективной модели образовательной практики. Наши предложения - только один из таких концептов в прогнозировании развития синергетической парадигмы и внедрения конвергентных технологий в гуманитарной высшей школе.

\section{Список литературы}

1. Образование и культура: история и современность.- Томск: Изд-во Томского ун-та, 1989.- Текст: непосредственный.

2. Московский синергетический форум: Тезисы. - М.. 1996. - Текст: непосредственный. 
3. Уокер Т. Финская система обучения. Как устроены лучшие школы в мире /Т. Уокер.-М.: Альпина паблишер,2018.-256с.- Текст: непосредственный.

4. Ковальчук М.В. Конвергенция наук и технологий и формирование новой ноосферы /М.В. Ковальчук, О.С. Нарайкин, Е.Б. Яцишина.- Текст: непосредственный //Российские нанотехнологии.- 2011.-№ 9-10.

5. Журавлева Е.Ю. Эпистемические обещания цифровых гуманитарных наук /Е.Ю. Журавлева.- Текст: непосредственный //Вопр. философии.- 2014.№9.- С. 91-97.

6. Дулатова А.Н. Тенденция к конвергенции профессий: прогностическая модель /А.Н. Дулатова.- Текст: непосредственный //Образование и наука в высшей школе: современные тренды: матер. Междунар. науч.-практ. конф. (Краснодар октябрь-ноябрь 2016).- Краснодар: КГИК,2016.-С.135-141. 